\title{
OECD Ülkelerinde Genişletici Maliye Politikalarının Ekonomik Büyüme Üzerine Etkisi
}

\section{The Effect of the Expansionary Fiscal Policies on Economic Growth in OECD Countries}

Hilmi Çoban ${ }^{1}$

Fatih Deyneli ${ }^{2}$

\section{ARTICLE INFO}

Submitted : 07.11 .2018

Revised : 05.04.2019

Accepted : 18.04.2019

Available : 30.07.2019

iThenticate similarity score: $10 \%$

JEL classification: $\mathrm{H} 60, \mathrm{H} 62, \mathrm{O} 47$

Keywords:

Fiscal Impulse, Keynesian Economics, Fiscal Policy, Budget

\begin{abstract}
A B S T R A C T
Although monetary and fiscal policies are discussed in different economic approaches, the main discussion is focused on fiscal policy. Because while the central bank leads the monetary policy independently with its own policy goals and tools, the government leads the fiscal policy via budget as a basic tool of the economic policy.

In this study, we analyze the relationship between economic growth and fiscal impulse which is used to measure changes in public budget impacts by using the panel data analysis with fixed effects in 33 OECD countries. We use the International Monetary Fund and World Bank data. According to the results; the expansionary effect of fiscal policies has no effect on economic growth between the period of 2011-2017.
\end{abstract}

Cite this article as: Çoban, H. \& Deyneli, F. (2019). "OECD Ülkelerinde Genişletici Maliye Politikalarının Ekonomik Büyüme Üzerine Etkisi", International Journal of Public Finance, 4(1), 59-74.

1 Assoc. Prof. Dr., ORCID: 0000-0001-6351-6547, Hacı Bayram Veli University, Department of Public Finance, Ankara, Turkey, hilmicoban@hbv.edu.tr

2 Assoc. Prof. Dr., ORCID: 0000-0003-1867-1075, Pamukkale University, Department of Public Finance, Denizli, Turkey, fdeyneli@pau.ed.tr 


\begin{tabular}{|c|c|}
\hline MAK & \\
\hline Gönderme: 07.11 & \multirow{7}{*}{$\begin{array}{l}\text { Para ve maliye politikaları farklı ekonomik yaklaşımlar içinde ele alınan } \\
\text { politikalar olmasına rağmen, yaklaşımlar arasındaki temel tartışma maliye } \\
\text { politikası üzerindedir. Bunun nedeni, para politikasına amaç ve araç } \\
\text { bağımsızlığı çerçevesinde merkez bankası yön verirken; hükümetin bütçe } \\
\text { aracılı̆̆ı ile maliye politikasını temel iktisat politikası aracı olarak } \\
\text { kullanmasıdır. } \\
\text { Bu çalışmada, kamu bütçesindeki meydana gelen değişmeleri ölçmek } \\
\text { içinde kullanılan mali etki ile ekonomik büyüme arasında ilişki } 33 \text { OECD } \\
\text { için panel veri analizi sabit etkiler modeli kullanılarak analiz edilmiştir. } \\
\text { Çalışmada Uluslararası Para Fonu ve Dünya Bankası verileri kullanııı̧ıtır. } \\
2011-2017 \text { yılları arasını kapsayan analiz sonuçlarına göre; maliye } \\
\text { politikalarının genişletici etkisinin ekonomik büyüme üzerindeki etkisinin } \\
\text { olmadığı̈ı̈rülmektedir. }\end{array}$} \\
\hline Düzeltme : 05.0 & \\
\hline Kabul & \\
\hline Yayın & \\
\hline $\begin{array}{l}\text { iThenticate benzerlik } \\
\text { oranı: } \% 10\end{array}$ & \\
\hline & \\
\hline $\begin{array}{l}\text { Anahtar Kelimeler: } \\
\text { Mali etki, Keynesyen } \\
\text { iktisat, Maliye Politikası, } \\
\text { Bütçe }\end{array}$ & \\
\hline
\end{tabular}

\section{Giriş}

Ülkelerin yaşadıkları iktisadi sorunların çözümüne ilişkin başvurdukları temel araçlardan birisi maliye politikasıdır. 1929 ekonomik krizi başta olmak üzere ardından yaşanan tüm ulusal ve uluslararası krizlerin etkilerinin azaltılmasına yönelik olarak, farklı yoğunluklarda da olsa kullanılan maliye politikasının etkinliğinin ölçülmesi, politika kullanımının yaygınlaşmasına veya daha çok olumsuz eleştiri ile birlikte kullanımının azaltılmasına neden olabilmektedir. Maliye politikasının etkinliği, çarpan kavramı ile ölçülmesinin yanında, son yıllarda mali etki kavramı ile de değerlendirmeye tabi tutulmaktadır. Mali etki kavramı, esasen maliye politikalarının ekonomi için uyarıcı nitelikteki özelliğini ifade etmektedir. Chand (1977) tarafından, bütçe uyarıcı etkisi olarak isimlendirilen ve ölçülen mali etki kavramı, farklı yaklaşımlarla ölçülmüş ve maliye politikasının etkinliği için yeni bir bakış açısı ortaya koymuştur. Gerek IMF gerekse OECD tarafından yapılan hesaplamalarda kamu harcamaları ve vergilerin, potansiyel ve fiili milli gelir üzerindeki etkileri birlikte ele alınmış olması, mali etki kavramının Chand (1977) tarafından ortaya konan "bütçe uyarıcı etkisi" etrafında incelendiğini ortaya koymaktadır.

Bu çalışmada -özellikle 2008 yılı krizi sonrasında yaşanan gelişmeler dikkate alınarak- Keynesyen iktisadın çözüm önerilerinden biri olan genişletici bütçe uygulamalarının ekonomik büyüme üzerindeki ektisi incelenecektir. Çalışma 2011-2017 yılları arasını ve 33 OECD ülkesini kapsamaktadır. Çalışmada panel veri analizi sabit etkiler modeli kullanılmıştır. Bütçe uygulamalarının ekonomi üzerindeki genişletici (veya daraltıcı) etkisini incelemek için Uluslararası Para Fonu tarafından hesaplanan mali etki ölçümü bağımlı değişken olarak kullanılmıştır. Dünya Bankası tarafından yayınlanan ekonomik göstergeler ise açıklayıcı değişken olarak kullanılmıştır.

Çalışmanın ilk bölümünde maliye politikasının ekonomi üzerindeki etkinliği üzerinde yapılan tartışmalara yer verilmiştir. İkinci bölümde literatür taraması yer almaktadır. Üçüncü bölümde yönteme, model ve verilere yer verilirken, dördüncü 
bölümde elde edilen bulgular sunulmuştur. Sonuç bölümde ise analiz sonucunda elde edilen bulgular ışığında değerlendirmeler yapılmıştır.

\section{Maliye Politikasının Ekonomi Üzerindeki Etkinliği}

Ekonomik sorunların çözümüne ilişkin olarak uygulanacak iktisat politikalarının farklılığı, politika uygulayıcılarının zihnindeki ekonomik yaklaşımların farklılığı ile doğru orantılıdır. Temelde farklı ekonomik yaklaşımlar içinde ele alınan politikalar para ve maliye politikalarıdır, ancak iktisadi yaklaşımlar arasındaki temel tartışma alanı maliye politikaları üzerinedir. Dünyada neo-liberal politikaların uygulama alanının genişlemesi ile para politikalarının temel uygulayıcısı konumundaki merkez banklarının amaç ve araç bağımsızlık dereceleri artmış ve para politikaları piyasa mekanizması içinde çözümler sunma yönünde değişmiştir. Maliye politikaları ise kullandığı araçlar itibariyle kamu otoritesinin elindeki en temel iktisat politikası aracı olarak kullanılmaya devam etmiştir.

Fizyokratlar ve devamında Klasik İktisadi Düşünce içinde devletin ekonomiye müdahalesinin oldukça sınırlı olması gerektiği belirtilmiştir. Fizyokratlar, merkantilistler tarafından ortaya atılan devlet müdahalelerinin etkinsizliğini vurgulayarak burjuvazinin karşısında durmuştur (Charbit, 2002: 867). “Doğal Düzen” ekonominin genel kurallarını içerir ve toplum düzenine uygulanması durumunu ifade eder (Neill, 1949: 536). Net hasılayı (ürünü) arttıracak unsur doğal düzendir ve müdahale edilmemelidir (Spengler, 1945: 328). Fizyokratlar klasik iktisadi düşüncenin temellerini atması bakımından oldukça önemlidir ve maliye politikasının kullanımının oldukça sınırlandı̆̆ı, doğal düzen içinde oluşturulan ekonomik düzenin, net hasılayı arttıracak temel unsur olarak görüldügü bir iktisadi yaklaşımı ifade etmektedir.

Klasik iktisadi düşünce, özellikle ücretlerin ve fiyatların esnekliğine odaklanarak, ekonominin tam istihdamda dengede olduğunu ve uygulanacak maliye politikasının tam dışlamaya neden olacağını belirtmiştir. Adam Smith kişinin tamamen kendi özel faydasına odaklı biçimde çalışırken, görünmez el ile yönetilen piyasa süreci sonucunda, kişinin niyetinin parçası olmayan bir sonu teşvik ettiğini belirtmiştir (Gramp, 2000: 445). Bireylerin toplumsal çıkarlara ilişkin sahip oldukları dürtüler olmasa dahi, mal ve faktör piyasasında var olan fiyatların ve ücretlerin esnekliği ile ifade edilen görünmez el, bireysel çıkarların amacı içinde olmayan sonuçların ortaya çıkmasını sağlayacaktır.

Adam Smith kamu kurumlarının yaptığı harcamaların finansmanının mümkün olduğunca kullanıcı ücretleri ile finanse edilmesini gerektiğini belirtmiştir (Eecke, 2003: 705). Bu durum kamu gelirlerinin kamu harcamalarının finansmanı sağlama dışında başka fonksiyonu olmadığını ifade etmektedir. Maliye politikasının bir diğer önemli aracı olan kamu gelirlerinin etkinliğini sınırlayan bu yaklaşım, maliye politikasının ekonomi üzerindeki etkisinin de hafiflemesi sonucunu doğurmaktadır. 1929 Büyük Buhran öncesinde Birinci Dünya savaşının da etkisiyle zayıflayan Avrupa ülkelerinin aksine, Amerika'da ortaya çıkan yüksek düzeyde yatırım, önemli verimlilik artışları, istikrarlı fiyatlar, yüksek ücretler ve yüksek şirket karları ile birleşerek, Amerikan borsasında fiyatların şişmesine neden olmuştur (Crafts \& Fearon, 2010: 289). 
Amerika'daki hisse senetlerinin fiyatlarının, şirketlerin reel değerlerinden çok daha fazla, aşırı şekilde yükselmesi ve bir balon oluşturması ile başlayan süreç, geleneksel iktisat olarak literatürde ifade edilen klasik iktisadi düşüncenin temel ilkelerinin sorgulanması sonucunu doğurmuştur.

Büyük buhranın ölçek ve süre açısından diğer krizlerden farklı olmasının arkasında, beklenmedik teknolojik gelişmenin oluşturduğu şok, vakıfların, tüketici tercihlerinin veya devletin istikrarlı büyümeyi olumsuz etkileyen davranış ve politikaları bulunmaktadır (Cole \& Ohanian, 1999: 3). Birinci Dünya Savaşı sonrasında Amerika'da özellikle otomobil ve endüstride yaşana gelişmeler, Amerika'da arzın artmasına neden olmuş ve artan üretim sonucu şirketlerin hisse senetleri değerinde de artışlar ortaya çıkmıştır (Buluş \& Kabaklarlı, 2010: 2). Klasik iktisadın özellikle ekonomide arz veya talep fazlası olmayacağına ilişkin genel iddiasının, ortaya çıkan arz fazlasına ve fiyatların düşmesine rağmen talebin yeterince artmaması nedeniyle gerçekleşmemesi, klasik iktisadın önemli ayaklarından birinin boşa çıkmasına neden olmuştur. 1929 Büyük Burhan'ının ve 1930 'lu yıllarda yaşanan düşük büyümenin birçok sebebi vardır ve bu konuda çok farklı teoriler mevcuttur. Ancak krizin sebebinin maliye politikası olmadığı konusunda fikir birliği bulunmaktadır (McGrattan, 2012: 1515). 1930'lu yıllarda maliye politikası sonucu toplam talepte ortaya çıkan artışın, özellikle GSMH'deki payı açısından ele alındığında ekonominin tamamını etkileyecek düzeyde önemli olmadığı görülmektedir (Brown, 1956: 864-865). Esasen bu durum, 1930'lu yılların başında maliye politikasının çok yoğun olarak kullanılmadığı ve bu nedenle yaşanan büyük buhranın derinliği ve ölçeğine ilişkin maliye politikasının herhangi bir etkinliğinin bulunmadığını göstermektedir. Büyük buhrana ilişkin olarak yapılan analizlerde genel kabul bu şekildedir. Ancak bu görüşlerin aksine, krizin bu ölçüde büyük olmasını maliye politikasına bağlayan analizler de bulunmaktadır.

McGrattan, genişletilmiş büyüme modellerini kullanarak yaptığı analizde, Büyük Buhran üzerinde maliye politikasının etkisinin büyük olduğu sonucuna ulaşmıştır. Modelde McGrattan, kamu gelirlerini ve kamu harcamalarını genişletmiş, kamu gelirlerine diğer modellerin aksine, kurumlar vergisi dışında, emlak, aşırı kazanç, menkul kıymet vergisi ve dağıtılmayan kazançlar üzerindeki vergileri de dahil etmiş ve kamu gelirlerini genişletmiştir. Bunun sonucu olarak maliye politikasının büyük buhran üzerinde etkisi olmadığı iddiasını ret etmiştir (McGrattan, 2012: 1516). Analizde özellikle kar payı ve dağıtılmayan karlar üzerindeki vergilerin yatırımları azalttığı iddiası, vergilerin daraltıcı etkisinin ekonomi üzerinde oldukça etkin olduğu ve yaşanan krizde maliye politikasının rolü olduğu savını desteklemek için kullanıımıştır.

Keynesyen iktisatçılar ve Chicago iktisatçıları, büyük buhranın atlatılabilmesi için kamu işlerine yönelik politikalar geliştirilmesi gerektiğini belirtmiştir. Chicago iktisatçıları politika önerilerini 3 temel ayak üzerine oturtmuştur. Arz ve talep arasında senkronizasyon eksikliğinin varlığı, fiyatların sert bir şekilde aşağıya düşmesi ve para politikasının etkisizliğidir (Caldentey, 2003: 18). Klasiklerin arz ve talebin her zaman dengede olduğu iddiasını ret ederek, etkinsiz olan para politikaları yerine maliye politikalarının kullanıması gerektiğini ortaya koymuşlardır. Fiyat mekanizması ile sağlanması beklenen arz talep eşitliği yerine, uygulanacak maliye politikalarının 
ekonomik dengeyi sağlayacağını, para politikasının ekonomik dengeyi sağlama bakımından etkisizliğine vurgu yaparak, uygulanacak kamusal politikaların fiyatların ve maliyetlerin düşmesi, üretimin arttırılması bakımından önemli olduğunu belirtmişlerdir.

Keynes'in krize yönelik sunduğu tedavinin merkezinde, iyi mikro niyetlerin, kötü makro sonuçları olabileceği, ekonominin dengesinin eksik istihdamda olabileceği ve bu durumdan çıkışın maliye politikasının kullanııması ile olacağı yatmaktaydı. Keynes'in tedavi önerisinde para politikası hala baskın olsa bile para talebinin elastik, yatırım fonksiyonun ise inelastik olması, para politikasının makro bir yönetim anlayışı içinde ekonomi üzerinde etkili olamayacağı belirtilmiştir (Musgrave, 1987: 171). Keynesyen modelde para talebinin faize olan duyarlılığının yüksek olduğunu, buna karşın yatırımların faiz esnekliğinin düşük olması nedeniyle yatırım talep doğrusunun dik bir konumda olduğu kabul edilmiştir. Para talep eğrisinin nispeten yatay, yatırım talep doğrusunun nispeten dik bir konumda olduğunun kabulü, para politikasının etkinliğini azaltırken, maliye politikasının milli geliri arttırıcı etkisinin yüksek olduğunu ortaya koymaktadır. Keynes, 1933 yılında Başkan Roosvelt'e gönderdiği ve New York Times tarafından yayınlanan mektubunda ve 1934 yılında Roosvelt ile olan görüşmesinde, bütçe açığına güvenilmesinin, ucuz ve bol kredi ile para politikasının kullanılmasının ve harcamaların üçte bir oranında arttırılmasının Büyük Burhan'ın etkilerinin azaltacağını belirtmiştir (Musgrave, 1987: 172-173). Keynes esasen para politikasının kullanılmasına karşı olmamak ile birlikte, belli bir düzeyden sonra para talebinin faiz esnekliğinin sonsuz olduğu ve bu noktadan sonra para arzında yapılacak bir değiş̧ikliğin, milli gelir üzerinde her hangi bir etkinliğinin olmayacağını ifade etmiştir. "Likidite Tuzağı" ile ifade edilen bu durum, para politikasının etkinliğinin belli bir düzeyde sıfırlanmasını ifade etmektedir (Steindl, 1966). Maliye politikası açısından ise böyle bir durum söz konusu değildir. Uygulanan genişletici maliye politikasının makroekonomiyi dengeleyici etkisi yanında, ekonomik büyümeyi sağlayacak ve ekonomiyi tam istihdama doğru taşıyacaktır.

1920'li yılların sonları ile 1960 yılları arasında çoğu politik lider ve iktisatçı kamu harcamaları, vergiler ve bunların ulusal ekonomi üzerindeki etkileri açısından daha önceki görüşlerini değiştirmiş ve telafi edici bütçe kavramı ile önemli olanın ekonomide istihdamın arttırılması veya tam istihdama ulaşılması olduğunu belirterek, bütçe açıklarını desteklemiştir (Thorndike, 2010: 95). Bu dönemde uygulanan genişletici maliye politikalarının ve bütçe açıkları nedeniyle devletlerin kamu borç yükleri sürekli artmıştır. Artan bu bütçe yükleri ile ortaya çıkan ve sürekli artan finansman ihtiyacı ülkeleri bir borç krizine doğru sürüklemiştir. Keynes'in uzun dönemde bütçe denkliğine verdiği önem, politikacılar tarafından çok dikkate alınmamış ve artan bütçe açıklarını borçlanma ve para arzı artışları ile finanse etme çabaları ülkeleri bir borç krizine doğru sürüklemiştir. Bu dönemden sonra maliye politikasının kullanımı ve mili gelir üzerindeki etkinliği daha çok tartışma konusu olmuş ve 1929 Büyük Buhran ile kendini kabul ettiren ve yaygın biçimde uygulanan maliye politikasının kullanım alanı daralmıştır.

1980'li yılların başında başta Latin Amerika ülkeleri olmak üzere, gelişmekte olan ülkelerin çoğunda ortaya çıkan OPEC krizinin de etkisi ile borçlanma ihtiyacı artmış ve borcu ödeyebilme güçleri azalmıştır (Ay \& Uçar, 2015: 17).1980'li yılların başında 
yaşanan borç krizi, ekonomik büyüme üzerinde mali açıkların negatif etkisini ortaya koyan iktisat teorilerinin gelişmesine yol açarken, mali açıkların negatif etkisi üzerindeki uzlaşma "Washington Uzlaşısı" sürecini hızlandırmıştır (Neto ve Vernengo, 2004: 333). Bretton Woods sisteminin dalgalı kur rejimi ile birlikte kenara itilmesi, sermaye akışının hızlanması, dış ticarete yönelik engellerin kaldırılması ve Washington Uzlaşısı ile hızlanan süreç, para politikasının tek enstrüman olarak kullanımına odaklanan, fiyat istikrarını önemseyen, maliye politikasını sınırlandıran bir iktisadi düşünce sistemine doğru ilerlemiştir (Blanchard vd., 2010). Neo liberal politikaların hâkim olduğu bu dönemde, her ne kadar maliye politikasının kullanımına yönelik politikalar sınırlandırılmış olsa da, maliye politikasının etkinliğine yönelik tartışmalar ve analizler sürekli biçimde yapılmaya devam etmiştir.

\section{Literatür Taraması}

Keynesyen modelde maliye politikasının etkisini gösteren temel gösterge "çarpan” kavramıdır. Maliye politikasının etkinliğini ölçmeye çalışan çoğu çalışma kamu harcamaları çarpanı üzerinde durmuş ve ekonomik durgunluk üzerinde maliye politikasının etkinliğini bu kavram ile açıklamaya çalışmıştır. Konjonktüre karşı uygulanan maliye politikasının etkisini anlamak için, gözlemlerden farklı olarak karşıolgusal etkinin tahmin edilmesi gereklidir (Parker, 2011: 706). Uygulanan maliye politikası sonucu birçok farklı sonuç gözlemlenebilir, ancak bu etkilerden en önemlisi ya da hedeflenmiş olan temel değişken üzerinden etkinin ölçülebilmesini ifade eden karşıolgusal etkiler, kamu harcamaları çarpanını anlama açısından oldukça önemlidir. Tarihsel açıdan özellikle durgunluğa, resesyona karşı uygulama alanı bulan maliye politikası ve bu politikaların etkinliğini gösteren çarpan etkisi, maliye politikasının milli gelir üzerindeki etkisi üzerine yoğunlaşmaktadır.

Mali çarpan olarak da ifade edilen bu kavram, kamu harcamaları veya vergi gelirleri yoluyla mali açıkta ortaya çıkacak bir dışsal değişkenin, milli gelir üzerinde yaptığı değişikliği gösteren bir orandır (Spilimbergo vd., 2009: 2). Blanchard \& Perotti, Amerika için mali çarpanı 1947-1-1997-4 arasında çeyrek dönemlik verilerini kullanarak VAR analizi ile tahmin etmiş ve mali çarpanı çeyrek dönem için 0.8, iki yıl için ise 0.5 olarak hesaplamıştır (Blanchard \& Perotti, 2002). Mali çarpanın milli gelir üzerindeki etkisinin 1'den küçük olması, uygulanan genişletici politikaların milli geliri kendisinden daha az etkilediğini göstermektedir.

Perotti daha sonra 5 OECD ülkesi (Avustralya, Kanada, Batı Almanya, Ingiltere ve Amerika) için, 1960-2001 verilerini VAR analizi çerçevesinde değerlendirerek yaptığı çalışmada, 1960-1-1979-4 dönemini ve 1980-1 ile 2001-4 arasındaki dönemi farklı ele almış ve bütün ülkelerde gerek bir çeyreklik, gerekse 2 yıllık analizlerin neredeyse tamamında 1980 sonrası çarpanın daha düşük çıktığı sonucunu elde etmiştir (Perotti, 2005). Auerbach \& Gorodnichenko (2012), genişleme ve daralma dönemleri için çarpan katsayısını ayrı ayrı hesaplamaya çalışmış ve ekonomin durgunluk dönemlerinde uygulanan maliye politikalarına ilişkin mali çarpanın 1.4 olduğunu, fakat genişleme 
dönemlerinde mali çarpanın 0.0 ve hatta 2 yıllık süreçte -0.1 olduğunu ortaya koymaktadır.

Mencinger vd. (2017) OECD ülkeleri için 1980-2014, AB ülkeleri için ise 19952014 yılları arasındaki çeyrek dönemlik verileri kullanarak yaptıkları çalışmada, 2008 krizi sonrası her iki ülke grubu için maliye politikasının etkinliğini ifade eden çarpanın büyüdüğü sonucunu elde etmişlerdir. Ayrıca $28 \mathrm{AB}$ üyesi ülke içinde çekirdek ve sonradan katılan ayrımı yaparak, sonradan katılan ülkelerde maliye politikası çarpanını daha büyük olduğu sonucuna ulaşmıştır (Mencinger vd.,2017: 459). Skrbic (2018) Hırvatistan ekonomisi için 2010-2016 yılları arasındaki aylık verileri kullanarak, maliye politikasını etkinliğini ölçmeye çalışmıştır. Çalışmada maliye politikasını Hırvatistan ekonomisi üzerinde çok önemli bir etkisinin olduğu sonucuna ulaşılmıştır. Özellikle istihdam ve çıktı miktarını maliye politikasına pozitif yönde tepki verdiği yönünde sonuç elde edilmiştir (Skrbic, 2018: 95).

Dökmen \& Vural (2011), Türkiye'nin 1990:1, 2010:4 dönemine ait verileri kullanarak yaptıkları analizde, kamu harcamalarındaki pozitif bir şok karşısında gayrisafi yurtiçi hasılanın pozitif tepki verdiği bulgusuna ulaşmıştır (Dökmen \& Vural, 2011: 131). Afonso \& Claeys, 1970 ile 2004 yılları arasında Almanya, Fansa, Portekiz ve İspanya gibi ülkelerde, maliye politikasını milli gelir üzerindeki etkisini VAR analizini kullanarak ortaya koymaya çalışmışlardır ve ekonomik patlamalar (toparlanma) sırasında vergi oranlarının düşmesini kamu harcamalarındaki kısıntılar takip etmediği için, zamanla yapısal açıkların bütçe açıklarının oluştuğunu belirtmişlerdir. Bu sonucu doğuran temel etmen, maliye politikasının özellikle uzun dönemde milli gelir üzerinde etkili olmadığıdır (Afonso \& Claeys, 2008).

Ilzetzki vd. (2011) 44 ülke için yaptıkları çalışmada, endüstrileşmiş ülkelerde mali çarpanın, gelişmekte olan ülkelere göre daha büyük olduğu sonucuna ulaşmışlardır. Ayrıca açık ekonomilerde çarpan katsayısının kapalı ekonomilere göre da düşük olmasının yanı sıra, yüksek borçlu ülkelerde mali çarpanın etksinin sıfır düzeyinde olduğu bulgusunu elde etmişlerdir (Ilzetzki vd., 2011: 26). Şen \& Kaya (2012) Türkiye için 1980-2010 yılları arasındaki yıllık verileri kullanarak yaptıkları çalışmada mali etkinin, toplam talebi ve ekonomik büyümeyi etkilemede önemli bir enstrüman olduğu ve mali etkinin artması ile ekonomik büyümenin pozitif yönde etkilendiği sonucunu elde etmişlerdir (Şen \& Kaya, 2012: 74).

Ülke maliye politikaları ve kullandıkları mali araçlar açısından kıyaslanırken, ülkelerin bütçeleri içinde kamu harcamalarının veya kamu gelirlerinin payı ele alınmaktadır. Maliye politikasının ekonomi üzerindeki etkili olup olmadığına bakmadan, maliye politikasının durumunun mevcut bütçe pozisyonu açısından ele alınması yanıltıcı olabilir (Heller vd., 1986: 2). Maliye politikalarının ekonomi üzerindeki etkilerinin ölçümünde kullanılan göstergelerden birisi mali uyarı etkisi, mali dürtü olarak da ifade edilebilen mali etki (fiscal impulse) kavramıdır. Esasen literatüre mali etki olarak dahil edilen kavram yerine, maliye politikalarının uyarıcı etkisine vurgu yaparak dürtü, uyarıcı etki şeklinde kullanılmasının daha doğru olduğu kanaatine sahibiz. Ancak çalışmada literatürdeki diğer kullanımlara benzer şekilde mali etki olarak kullanılacaktır. 
Mali etki, mali politikadaki değişikliklerin ekonomik faaliyetler ve diğer ekonomik değişkenler üzerindeki etkisini ölçmek için kullanılan mali çarpan kavramı ile karıştırılmaktadır. Mali etki, hükümetin bütçe dengesinde, politikaya dayalı bir değişme olup olmadığını ortaya koymaktadır. Mali çarpan ise, maliye politikasındaki değişkenlerin ekonomik faaliyetler ve değişkenler üzerindeki etkisinin ne olduğunu ortaya koymaya çalışmaktadır (Schinasi \& Lutz, 1991: 1). Chand, mali etki kavramını ilk kez "bütçe uyarı etkisi" şeklinde tanımlamıştır ve en basit şekli ile şu şekilde hesaplamıştır (Chand, 1977: 414).

$$
\text { Bütçe Uyarıcı Etkisi (Dürtüsü) }=\frac{G-T-\left(G_{-1}-T_{-1}-y T_{-1}\right)}{G_{-1}}
$$

\section{y = Mevcut GSYİH büyüme oran}

Mali etki ölçümleri, bütçenin ekonomi üzerindeki değişen etkisini değerlendirmek için kullanılmıştır. Buna göre potansiyel büyümeyi aşan harcama büyümesi genişletici, potansiyel büyümeyi aşan gelir artışları ise daraltıcı kabul edilmektedir. Bütçe dengesindeki değişim ile, potansiyel milli gelirdeki değişimi kıyaslayarak elde edilen mali etki, fiili bütçe açığının hızıı büyümesi durumunda, toplam talebe etkisi bakımından genişleyici olduğu kabul edilir (Chand, 1992).

IMF'nin Dünya Ekonomik Görünümü'nde yaptığı mali etki hesaplaması şu şekildedir (Chand, 1992: 1);

$$
\text { Mali Etki }=\left(\Delta G-g_{0} \Delta Y_{p}\right)-\left(\Delta T-t_{0} \Delta Y\right)
$$

"G" kamu harcamalarını, " $g_{0}$ kamu harcamalarının potansiyel GSMH içindeki oranını, "T" kamu gelirlerini, " $t_{0 "}$ kamu gelirlerinin fiili GSMH içindeki oranını ifade etmektedir. Buradan elde edilecek değerin pozitif olması, bütçenin harcama artış hızının, milli gelir artış hızından daha büyük olduğunu ve genişletici etkilerin ortaya çıktığını, negatif çıkması ise kamu gelirlerinin artış hızının milli gelirdeki artış hızından büyük olduğunu ve yıldan yıla bütçenin daraltıcı etkiye sahip olduğunu göstermektedir. Bütçe açığı açısından fiili bütçe açı̆̆ındaki artışın daha hızlı büyümesinin, mali uyarıcıların genişletici yönde çalıştığını göstermektedir.

OECD mali etki hesaplaması, IMF tarafından yapılan hesaplamaya oldukça yakındır. En önemli farklııı, OECD hesaplamaya ilişkin formülde harcamaların ve kamu gelirlerinin potansiyel milli gelirdeki değişmeye olan esnekliklerinin kullanılmasıdır. Bu durum OECD hesaplamasında otomatik stabilizatörlerin modele dahil edildiğini göstermektedir. OECD mali etki formülü (Heller vd., 1986: 4);

$$
\text { Mali Etki }=\Delta G_{p}-\Delta T_{p}+\left(\gamma \frac{G_{t-1}}{Y_{t-1}}-\epsilon \frac{T_{t-1}}{Y_{t-1}}\right) \Delta Y^{p}
$$

\footnotetext{
$\Delta G_{p}=$ Politika değişikliğinden kaynaklanan kamu harcamalarındaki değişim

$\Delta T_{p}=$ Politika değişikliğinden kaynaklanan vergi gelirlerindeki değişim
} 
$\Delta Y^{p}=$ Potansiyel milli gelirdeki değişim

$Y=$ Kamu harcamalarının potansiyel gelirdeki değişme gösterdiği esneklik

$E^{E}=$ Vergi gelirlerinin potansiyel gelirdeki değişmeye gösterdiği esneklik

Kamu harcamalarındaki değişim ile vergi gelirlerindeki değişime, kamu harcamaları ve vergi gelirlerinin potansiyel milli gelirdeki değişime bağlı olarak gösterdikleri değişimlerin de eklenmesi, mali etkinin ölçümünü IMF hesaplamasından oldukça farklılaştırmıştır.

Maliye politikasının ekonomi üzerindeki etkinliğini ölçmek için kullanılan genel kavram mali çarpandır. Ancak farklı bir bakış açısıyla bütçe açığındaki değişimi, ekonominin fiili ve potansiyel büyümesi ile ilişkilendirerek hesaplanan mali etki katsayısı da IMF ve OECD başta olmak üzere birçok iktisatçı tarafından yaygın biçimde kullanılmaktadır.

\section{Yöntem, Model ve Veriler}

Bu çalışmada genişletici maliye politikaları ile ekonomik büyüme arasındaki ilişkiyi ortaya koymak için panel veri analizi kullanılmıştır. Panel veri analizi, zaman serisi ve yatay kesit verilerine göre daha büyük bir veri kümesinden yararlanma olanağı vermektedir. Gözlem sayısının artması daha doğru ve daha güvenilir parametre tahminleri üretir. Bu aynı zamanda, daha fazla değişkenlik, değişkenler arasında daha az doğrusallık, daha fazla serbestlik derecesi ve daha etkin bir model sağlamaktadır (Baltagi, 2008; Hsiao, 2003).

Geleneksel bir panel veri modeli denklem 1'deki gibi gösterilebilir.

$$
\begin{aligned}
& y_{i t}=\propto_{i}+X_{i t}^{t} \beta+u_{i t} \\
& i=1, \ldots \ldots \ldots, N \\
& t=1, \ldots \ldots \ldots, N \\
& u_{i t=\mu_{i}}+v_{i t}
\end{aligned}
$$

Modelde i ülke, firma gibi yatay kesit boyutunu gösterirken, $\mathrm{t}$ ise zaman boyutunu, $a_{i}$ ise sabit terimi, $\beta \mathrm{Kx}$ ve $X_{i t}^{\prime}$ i kesitinde $\mathrm{t}$ zamanında $\mathrm{K}$ açıklayıcı değişkeninin gözlemini göstermektedir. ${ }^{\mu}$ gözlenemeyen değişkenleri, $v_{i t}$ ise hata terimini göstermektedir. Eğim katsayıları bütün bireyler için aynı olmakla birlikte, $\mu_{i}$ bireyden bireye değişmektedir. Eğim katsayılarında bireysel gözlenemeyen heterojenlik mevcuttur. Bireysel etkiler sabit ya da rassal olabilir (Hsiao, 2003). Bu çalışmada sabit etkiler modeli kullanılmıştır. 
2011-2017 yılları arasını ve 33 OECD ülkesini ${ }^{1}$ kapsayan çalışmada kullanılan ekonomik büyüme modeli başta Barro, (1996) büyüme modeli olmak üzere literatürdeki diğer çalışmalar göz önüne alınarak geliştirilmiştir. Çalışmada kullanılan model (1) nolu denklemdeki gibi yazılabilir;

büyüme $=\alpha_{i}+\beta_{1} G S Y I H_{-} k b_{t-1}+\beta_{2}$ mali_et $k i+\beta_{4}$ enflasyon $+\beta_{5}$ diş ticaret $+\beta_{6}$ sermaye $+\epsilon$ (1)

Formülde büyüme ekonomik büyümeyi göstermektedir. Modelde GSYiH'nın gecikmeli değeri açıklayıcı değişken olarak kullanılmıştır. Çeşitli büyüme modellerinde GSYIH'nın gecikmeli değerinin yakınsama değişkeni olarak kullanıldığı görülmektedir (Barro, 1996). Şartlı yakınsama teorisi gelir seviyesi düşük ülkelerin gelir seviyesi yüksek ülkeleri gelir düzeyi açısından yakalayacağını öne sürmektedir (Keefer \& Knack, 1997). Bu yüzden GSYiH değişkenin beklenen değeri negatiftir.

Çalışmada maliye politikalarının makroekonomik etkilerini ölçmek için kullanılan mali etki (Fiscal impluse) değişkeni kullanılmıştır. Konsept olarak mali etki, kamu harcamaları ve vergi politikalarındaki değişimlerin sonucu olarak kamu bütçesindeki meydana gelen değişmeleri ölçer. Mali etki kökeni mali olmayan olaylara dayanan mali dengedeki değişiklikleri görmezden gelir. Mali etki çoğu zaman maliye politikası çarpanı ile karıştırılır. Uygun şekilde yapılandırılmış mali etki ölçümü hem maliye politikasının bütçe çıktıları üzerindeki etkilerini ölçmede hem de maliye politikasındaki değişiklerin uluslararamasın karşılaştırmasında, -maliye politikasının zaman içinde değişip değişmediği gibi- yararı olur (Schinasi \& Lutz, 1991).

Literatürdeki çalışmalarda mali etkiyi ölçmek için farklı yöntemler kullanılmıştır. Bazı çalışmalar yapısal birincil bütçe dengesindeki ${ }^{2}$ (CAPB) meydana gelen değişmeyi mali etkiyi ölçmek için kullanmıştır. Bu çalışmalarda CAPB mali durum (Fiscal stance) olarak adlandırılmış ve CAPB artışı genişlemeci bir mali etkiyi temsil etmiştir (Janssen \& Philip, 2002). Buna göre mali durum aşağıdaki gibi değişmektedir;

CAPB $<0$ ise genişletici FS

CAPB $>0$ ise daraltıcı FS

Bu durumda mali etki ise aşağıdaki şekilde hesaplanmaktadır;

$$
m e=F S_{t-} F S_{t-1}
$$

Mali etkinin pozitif olması mali durumun genişleyici anlamına gelmektir. Bu çalışmada Uluslararası Para Fonu tarafından yayınlanan Mali Monitör 2018 veri setinde yer alan CAPB verileri kullanarak 33 ülke için mali etki hesaplanmıştır.

\footnotetext{
1 Avustralya, Avusturya, Belçika, Kanada, Şili, Çek Cumhuriyeti, Danimarka, Estonya, Finlandiya, Fransa, Almanya, Yunanistan, Macaristan, İzlanda, İrlanda, İsrail, İtalya, Japonya, Güney Kore, Letonya, Lüksemburg, Meksika, Hollanda, Yeni Zelanda, Norveç, Polonya, Portekiz, Slovenya, İsveç, İsviçre, Türkiye, Birleşik Krallık, Amerika Birleşik Devletleri.

2 Devresel hareketlerden etkilenmeyen faiz dışı bütçe dengesi.
} 
Literatürde yapılan çalışmalar da dikkate alınarak Model II'ye ve Model IV'e aşağıdaki kontrol değişkenleri eklenmiştir (Barro, 1996; Karadam, 2015; Sala-i-Martin, 1997; Temple, 1999).

Enflasyon: Ekonomi yazınında ekonomik büyüme ile enflasyon arasında tartışmalı bir ilişki olduğu söylenebilir (Temple, 1999). 1960lı yıllarda daha yüksek enflasyon, sermayeyi paraya göre daha cazip hale getirerek daha yüksek sermaye yoğunluğuna ve geçiş döneminde daha yüksek büyümeye yol açacağı düşünülse de ampirik çalışmalar enflasyon ile ekonomik büyüme arasında negatif bir ilişki olduğunu ortaya koymaktadır (Fisher, 1983). Barro (1995) yaptığı çalışmada ekonomik büyüme ile enflasyon oranı arasındaki ilişkiyi incelemiş ve iki değişken arasında negatif yönlü bir ilişki bulmuştur. Dolaysıyla enflasyon oranı (enflasyon), modele kontrol değişkeni olarak eklenmiştir.

Sermaye: Sermaye birikimi, kısa ve orta dönemde tasarruflar ve yatırım kararları ve çeşitleri aracılığı ile ekonomik büyümeyi etkilemektedir (Bassanini vd., 2001; Temple, 1999). Karadam (2015) yaptığı çalışmada brüt sermaye yatırımının GSYiH içindeki payı ile kişi başına düşen GSYiH arasında pozitif yönlü ve istatistiki olarak anlamlı bir ilişki bulmuştur. Dolayısıyla, sermaye değişkeni modele kontrol değişkeni olarak eklenmiştir.

Dış ticaret: Ekonomik büyüme ile dış ticaret (ihracat/ithalat) arasındaki ilişki ekonomi yazınında önemli bir yer tutmaktadır. Bu iki değişken arasındaki ilişkiler ampirik olarak hala araştırılıyor ise de, bu iki değişken arasında pozitif ilişkinin olduğu genel kabul olarak görülmektedir (Ram, 1987; Sağlam ve Egeli, 2018).

İşsizlik: Ekonomi yazınında, işsizlik ile ekonomik büyüme arasındaki ilişki genellikle Okun Kanunu ile açıklanmaktadır. Buna kanuna göre; işsizlik oranı ile büyüme arasında negatif bir ilişkinin olduğu kabul edilmektedir. Okun Kanunu hala en yaygın olarak kabul edilen ekonomi kurallarından biridir (Burda \& Wyplosz, 2001).

Çalışmada kullanılan değişkenler Dünya Bankası'nın Dünya Kalkınma Göstergeleri ve Uluslararası Para Fonu veri setinden elde edilmiştir. Tablo 1'de değişkenlerin açıklamaları yer almaktadır.

Tablo 1: Modelde Kullanılan Değişkenler ve Açıklamaları

\begin{tabular}{ccc}
\hline \hline Değişken Adı & Açıklama & Kaynak \\
\hline mali_etki & (CAPBt - CAPBt-1) & Uluslararası Para Fonu \\
& Kişi başına düşen GSYiH'nın yılık büyüme oranı. & Dünya Kalkınma Göstergeleri \\
büyüme & GSYiH'nın gecikmeli değerinin logaritmik formu & Dünya Kalkınma Göstergeleri \\
GSYiH & Brüt sabit sermaye oluşumu (\% GSYiH) & Dünya Kalkınma Göstergeleri \\
sermaye & Yıllık Enflasyon (\%) & Dünya Kalkınma Göstergeleri \\
enflasyon & Ihracat birim değer endeksinin ithalat birim değer endeksi & Dünya Kalkınma Göstergeleri \\
dış ticaret & içindeki oranı ile hesaplanan net barter endeksi. & \\
& işsiz olanların toplam iş gücü içindeki payı. & Dünya Kalkınma Göstergeleri \\
\hline \hline
\end{tabular}

Kaynak: Yazarlar tarafından oluşturulmuştur. 


\section{Bulgular}

Maliye politikasının etkinliğinin kişi başına reel GSYiH büyüme oranı üzerindeki etkilerinin araştırıldığı modeller Tablo 2'de gösterilmiştir. Hausman testi sonuçları sabit etkiler model tahminlerinin daha etkin olacağını gösterdiğinden dolayı bulguların yorumlanması sabit etkiler modelinin kullanıldığı modellerin sonuçlarına göre yapılacaktır. Tablo 2'de yer alan modeller 33 OECD ülkesi ve 19 Avrupa Birliği ülkesi için iki ayrı grup olarak tahmin edilmiştir. Model I ve Model II havuzlandırılmış (pooled) modelin, Model II ve Model IV rassal etkiler (random effects) modelinin, Model III ve Model VI sabit etkiler (fixed effects) modelinin sonuçlarını göstermektedir.

Tablo 2: OECD ve Avrupa Birliği Ülkeleri İçin Panel Veri Analizi Sonuçları

\begin{tabular}{ccccccc}
\hline \hline & \multicolumn{3}{c}{ OECD Ülkeleri } & \multicolumn{3}{c}{ Avrupa Birliği Ülkeleri } \\
\cline { 2 - 6 } GSYiH & Model I & Model II & Model III & Model IV & Model V & Model VI \\
& $-0.331^{* * *}$ & $-0.365^{* *}$ & $-21.49^{* * *}$ & $-0.404^{*}$ & -0.469 & $-30.00^{* * *}$ \\
mali_etki & $(0.118)$ & $(0.183)$ & $(3.933)$ & $(0.213)$ & $(0.339)$ & $(8.581)$ \\
& -0.169 & -0.189 & -0.101 & $-0.427^{*}$ & $-0.479^{*}$ & -0.280 \\
sermaye & $(0.132)$ & $(0.124)$ & $(0.124)$ & $(0.224)$ & $(0.210)$ & $(0.226)$ \\
& $0.193^{* * *}$ & $0.190^{*}$ & $0.343^{* * *}$ & $0.204^{* *}$ & 0.151 & $0.322^{*}$ \\
dış ticaret & $(0.0595)$ & $(0.0779)$ & $(0.126)$ & $(0.100)$ & $(0.129)$ & $(0.189)$ \\
& -0.00280 & 0.000762 & -0.0177 & 0.0529 & 0.0582 & 0.00737 \\
enflasyon & $(0.00686)$ & $(0.0100)$ & $(0.0242)$ & $(0.0418)$ & $(0.0622)$ & $(0.119)$ \\
& -0.0185 & $-0.206^{*}$ & $-0.635^{* * *}$ & -0.322 & -0.290 & $-0.615^{* *}$ \\
işsizlik & $(0.108)$ & $(0.119)$ & $(0.143)$ & $(0.216)$ & $(0.205)$ & $(0.243)$ \\
& -0.0115 & -0.0183 & $-0.287^{* *}$ & -0.0223 & -0.0271 & $-0.473^{* *}$ \\
sabit & $(0.0526)$ & $(0.0731)$ & $(0.139)$ & $(0.0773)$ & $(0.105)$ & $(0.222)$ \\
& $6.748^{*}$ & 7.720 & $575.2^{* * *}$ & 3.889 & 6.204 & $794.6^{* * *}$ \\
R-sqr & $(3.644)$ & $(5.452)$ & $(105.7)$ & $(7.269)$ & $(11.08)$ & $(229.1)$ \\
\hline F test & 0.121 & 0.0703 & 0.224 & 0.198 & 0.1246 & 0.229 \\
Hausman & & $17.48^{* * *}$ & & & $7.66^{* * *}$ & \\
N & 198 & 198 & 198 & 114 & 114 & 114 \\
\hline \hline
\end{tabular}

Kaynak: Yazarlar tarafından oluşturulmuştur.

Not: Standart hata parantez içinde gösterilmiştir.

${ }^{*} p<0.1, * * p<0.05,{ }^{* * *} p<0.01$ anlamlılık düzeylerinde istatistiki olarak anlamlıdır.

Analiz sonuçlarına göre; hem OECD ülkelerinde hem de Avrupa Birliği mali_etki ile ekonomik büyüme arasında negatif yönlü bir ilişki olmak ile birlikte (sırasıyla -0.101 ve -0.280), çıkan sonuçlar istatistik olarak anlamsızdır. Bu durum 2008 krizi sonrası uygulanan genişletici maliye politikasının ekonomik büyümeyi negatif etkilediğini göstermektedir. Sonuçların istatistiki olarak anlamsız çıkması da genişletici maliye 
politikalarının aslında etkinsiz olduğu, yani ekonomik büyümeyi etkilemediği şeklinde yorumlanabilir. Değişkenlerin işaretleri hem OECD ülkeleri hem de Avrupa Birliği ülkeleri için beklenen işaretlerdir. Ancak değişkenlerin anlamlılık düzeyleri ve katsayıları iki ülke grubu için farklılık göstermekledir. Model III 'de ve Model VI 'da yer alan sabit etkiler modelinin analiz sonuçları aşağıdaki şekilde özetlenebilir.

GSYH'nin katsayısı hem OECD ülkeleri hem de Avrupa Birliği ülkeleri için negatif ve 0.01 anlamlılık düzeyinde istatistiki olarak anlamlıdır (sırasıyla -21.49: $p<0.01$ ve -30.00: p 0.01). Negatif işaret gelir seviyesi yüksek ülkelerin daha yavaş büyüdüğünü, dolayısıyla işaretin gelir seviyesi düşük ülkelerin gelir seviyesi yüksek ülkeleri gelir düzeyi açısından yakalayacağını öne süren şartlı yakınsama teorisi ile uygundur (Herz \& Röger, 1995; Keefer \& Knack, 1997).

Sermaye değişkeninin katsayısı hem OECD ülkeleri hem de Avrupa Birliği ülkeleri için pozitif yönlü ve istatistiki olarak anlamlıdır (sırasıyla 0.343: $p<0.01$ : 0.322: $p<0.1$ ). Çalışma kapsamında yer alan ülkelerin, brüt sabit sermaye yatımları ekonomik büyümelerini pozitif yönde etkilemiştir. Geçmiş yıllarda yapılan çalışmalarda bu sonucu desteklemektedir (Karadam, 2015; Long \& Summers, 1991).

Enflasyon değişkeninin katsayısı hem OECD ülkeleri hem de Avrupa Birliği negatif yönlü ve istatistiki olarak anlamlıdır (sırasıyla -0.635: $p<0.001$ ve -0.615 : $p<0,05)$. Enflasyon ile ekonomik büyüme arasındaki negatif ilişki literatürde yapılan ve yukarıda bahsedilen çalışmalar ile aynı yönde olduğu görülmektedir. Sonuç olarak, düşük enflasyon oranın olduğu ülkelerde yüksek büyüme oranı olacaktır.

Enflasyon değişkenini diğer açıklayıcı değiş̧enlerden ayıran yönü, para politikasının bir sonucu olarak ortaya çıkmasıdır. Bu kapsamda para politikası değişkeni olarak da görülebilir. Önceki bölümlerde bahsedildiği gibi para ve maliye politikalarının etkinliği ve birbirleri ile olan etkileşimi iktisat yazınında tartışılan bir konu olmuştur. Çalışma kapsamındaki dönemde, ekonomik büyüme üzerinde maliye politikasının etkinliği yok iken para politikasının etkinliği hem OECD ülkelerinde hem de Avrupa Birliği ülkelerinde güçlü bir şekilde gözlenmektedir (Tablo 2 Model III ve Model VI).

Işsizlik değişkeninin katsayısı hem OECD ülkeleri hem de Avrupa Birliği negatif yönlü ve istatistiki olarak anlamlıdır (sırasıyla -0.287: $p<0.05$ ve -0.473 : $p<0.05$ ). İşsizlik ile ekonomik büyüme arasındaki negatif ilişki literatürde yapılan ve yukarıda bahsedilen çalışmalar ile aynı yönde olduğu görülmektedir.

\section{Sonuç}

1929 Ekonomik krizinin ardından politika uygulayıcı tarafından kullanımı yaygınlaşan Keynezyen iktisadi politikaların temelinde yatan maliye politikalarının, büyüme, işsizlik vb. makro değişkenler üzerindeki etkisi yaygın bir şekilde tartışılmaktadır. Etkisi ve büyüklüğü itibariyle 1929 Ekonomik Krizi ile karşılaştırılan 2008 krizi sonrası, ülkelerin krizden çıkmak için kullandıkları maliye politikaları, mali etki etrafında analiz edilmiş ve bütçenin milli gelir üzerindeki uyarıcı etkisini ifade eden 
mali etki ile büyüme arasındaki ilişki 2008 krizi sonrası için ortaya konulmaya çalışılmıştır.

2008 krizi sonrasında ülkeler genişletici para ve maliye politikaları uygulamaları ile krizin etkisini hafifletmek ve pozitif ekonomik büyümeyi sağlayarak işsizliği azaltmayı hedeflemişlerdir. Çalışma sonucunda mali etki ile ekonomik büyüme arasında söz konusu dönem için negatif yönlü bir ilişki elde edilmiştir. 2008 krizi sonrasında uygulanan genişletici maliye politikalarının büyüme üzerinde olumlu etkisi olmadığını gösteren bu durum, maliye politikalarının beklenen Keynezyen etkileri göstermediğini ortaya koymaktadır. Esasen söz konusu dönem için büyümeyi etkileyen temel faktörler düşük enflasyon, dış ticaret ve sermaye yatırımlarıdır.

Çalışma yapılan analiz sonuçlarına göre; 2008 krizi sonrası dönemde ülkelerin ekonomik büyümelerini maliye politikalarından ziyade para politikaları üzerine kurdukları ve politika tercihlerini para politikasından yana kullandıkları görülmektedir.. Ayrıca, bu dönemde ülkeler brüt sermaye yatırımları ve işsizlik ile mücadele ile ekonomik büyümelerini desteklemişlerdir. Düşük enflasyon ortamı, dışa açık bir ekonomi ve sermaye yatırımlarının arttırıması krizden çıkış yolu olarak kullanılmıştır. Bunun için ülkelerin, bütçelerini ekonomik büyümeyi etkileyen bu değişkenleri dikkate alarak dizayn etmeleri gerekmektedir.

\section{Kaynakça}

Afonso, A. \& Claeys, P. (2008). "The Dynamic Behaviour of Budget Components and Output", Economic Modelling, 25, 93-117.

Ay, H. \& Uçar, Ö. (2015). "Üç Küresel Ekonomik Krizin Analizi”, Sosyal Bilimler Enstitüsü Dergisi, 17(1), 11-32.

Baltagi, B.H. (2008). Econometric analysis of panel data, 4th ed., John Wiley \& Sons, Chichester, UK.

Barro, R.J. (1995). Inflation and Economic Growth, NBER Working Paper No. 5326.

Barro, R.J. (1996). Determinants of Economic Growth: A Cross-Country Empirical Study (NBER Working Paper No. 5698), Cambridge, MA.

Bassanini, A., Scarpetta, S., \& Hemmings, P. (2001). Economic Growth: The Role of Policies and Institutions. Panel Data Evidence from OECD Countries, OECD Economics Department Working Paper No. 283, Paris.

Brown, E.C. (1949). "Some Evidence on Business Expectations", The Review of Economics and Statistics, 31(3), 236-238.

Brown, E.C. (1956). "Fiscal Policy in the 'Thirties: A Reappraisal", The American Economic Review, 46(5), 857-879. 
Buluş, A. \& Kabaklarlı, E. (2010). "1929 Ekonomik Buhran İle Son Dönem Global Krizin Karşılaştırılması", Sosyal Ekonomik Araştırmalar Dergisi, 10(19), 1-22.

Burda, M., \& Wyplosz, C. (2001). Macroeconomics, Third Edition, Oxford University Press, New York.

Caldentey, E.P. (2003). “Chicago, Keynes and Fiscal Policy”. Investigación Económica, 62(246), 15-45.

Câmara, A.F.N. \& Vernengo, M. (2004) "Fiscal Policy and the Washington Consensus: A Post Keynesian Perspective", Journal of Post Keynesian Economics, 27(2), 333343.

Chand, S.K. (1977). "Summary Measures of Fiscal Influence", IMF Staff Papers, 24(2), 405-449.

Chand, S.K. (1977). "Summary Measures of Fiscal Influence", International Monetary Fund Staff Papers, XXIV(2), 405-449.

Chand, S.K. (1992) "Fiscal Impulses and Their Fiscal Impact", International Monetary Fund Working Paper, 92/38.

Charbit, Y. (2002). "The Political Failure of an Economic Theory: Physiocracy", Population-E, 57(6), 855-884.

Cole, H. L. \& Ohanian L.E. (1999). "The Great Depression in the United States From a Neoclassical Perspective", Federal Reserve Bank of Minneapolis Quarterly Review, 23(1), 1-24.

Crafts, N. \& Fearon, P. (2010) "Lessons from the 1930s Great Depression", Oxford Review of Economic Policy, 26(3), 285-317.

Dökmen, G. \& Vural, T. (2011). “Maliye Politikalarının Keynesyen Olmayan Etkileri: Türkiye Örneği", Maliye Dergisi, 161, 118-132.

Eecke, W.V. (2003) "Adam Smith and Musgrave's Concept of Merit Good", Journal of Socio-Economics, 31(6), 701-720.

Fisher, S. (1983). Inflation and Growth, NBER Working Paper Series No. 1235.

Grampp, W.D. (2000). "What Did Smith Mean by the Invisible Hand?", Journal of Political Economy, 108(3), 441-465.

Heller, P.S., Hass, R.D. \& Mansur, D.H. (1986). A Review Of The Fiscal Impulse Measure, International Monetary Fund, Washington D.C.

Hsiao, C. (2003). Analysis of panel data, 2nd ed, Cambridge University Press, Cambridge.

Ilzetzki, E., Mendoza, E.G. \& Végh, C.A. (2011). “How Big (Small?) are Fiscal Multipliers?", IMF Working Paper WP/51/12.

Janssen, J., \& Philip, R. (2002). "Indicators of Fiscal Impulse for New Zealand", The Treasury New Zealand Working Paper No. 02/30. 
Karadam, D.Y. (2015). “Reel Döviz Kurları ve Ekonomik Büyüme: Ülkelerarası Ampirik Bir Analiz", Pamukkale Journal of Eurasian Socioeconomic Studies, 2(1), 20-38.

Long, J.B., \& Summers, L.H. (1991). "Equipment Investment and Economic Growth", The Quarterly Journal of Economics, 106(2), 445-502.

LonRam, R. (1987). "Exports and Economic Growth in Developing Countries: Evidence from Time-Series and Cross-Section Data", Economic Development and Cultural Change, 36(1), 51-72.

McGrattan, E.R. (2012). "Capital taxation during the U.S. great depression", The Quarterly Journal of Economics, 127(3), 1515-1550.

Mencinger, J., Aristovnika, A. \& Verbič, M. (2017). “Asymmetric effects of fiscal policy in EU and OECD Countries", Economic Modelling, 61, 448-461.

Musgrave, R.A. (1987). “U.S. Fiscal Policy, Keynes, and Keynesian Economics”. Journal of Post Keynesian Economics, 10(2), 171-182.

Neill, T.P. (1949). "The Physiocrats' Concept of Economics P", The Quarterly Journal of Economics, 63(4), 532-553.

Parker, J.A. (2011). "On Measuring the Effects of Fiscal Policy in Recessions", Journal of Economic Literature, 49(3), 703-718.

Perotti R., (2005). Estimating the Effects of Fiscal Policy in OECD Countries, CEPR Discussion Paper No: 4842.

Schinasi, G.J., \& Lutz, M.S. (1991). "Fiscal Impulse”, IMF Working Paper No. 91/91.

Skrbic, M.D. (2018). "Dynamic Effects of Fiscal Policy in Croatia: Confronting NewKeynesian SOE Theory with Empirics", Zbornik radova Ekonomskog fakulteta u Rijeci/Proceedings of Rijeka Faculty of Economics, University of Rijeka, Faculty of Economics, 36(1), 83-102.

Spengler, J.J. (1945). "The Physiocrats and Say's Law of Markets", II. Journal of Political Economy, 53(4), 317-347.

Spilimbergo, A., Symansky, S. \& Schindler, M. (2009). Fiscal Multipliers, IMF Staff Position Note, SPN/09/11.

Sala-i-Martin, X. (1997). "I Just Ran Two Million Regressions", American Economic Review, 87(2), 178-183.

Steindl, F.G. (1966). "On the Existence of the Liquidity Trap", Nebraska Journal of Economics and Business, 5(2), 24- 33.

Şen, H. \& Kaya, A. (2012). "Mali Etki-Ekonomik Büyüme İlişkisi: Türkiye Ekonomisi Üzerine Bir Nedensellik Analizi (1980-2010)", Maliye Dergisi, 163, 61-75.

Temple, J. (1999). "The New Growth Evidence", Journal of Economic Literature, 37(1), 112-156.

Thorndike, J.J. (2010). "The Fiscal Revolution And Taxation: The Rise Of Compensatory Taxation, 1929-1938", Law and Contemporary Problems, 73(1), 95-122. 